\title{
Material para o Ensino de Ciências para Crianças com Limitações Comunicativas: Proposta de Análise Semiológica de Cartões do Picture Exchange Communication System
}

\author{
Material for Teaching Science for Children with Communicative \\ Limitations: Proposal for Semiological Analysis of Cards of the Picture \\ Exchange Communication System
}

\author{
Paulo César Gomes pc.gomes@unesp.br \\ Universidade Estadual Paulista - Unesp, Campus Botucatu, Grupo de Pesquisa Mídia-Educação, \\ Formação de Professores e Ensino de Ciências
}

Alexandra Bujokas de Siqueira alexandra.bujokas@midia-educacao.net Universidade Federal do Triângulo Mineiro - UFTM, Campus Uberaba

Tiago Fernando Alves de Moura ttiagomouraa@gmail.com

Universidade Estadual Paulista - Unesp, Campus Bauru, Grupo de Pesquisa Mídia-Educação, Formação de Professores e Ensino de Ciências

Resumo: Signos visuais estão presentes em materiais instrucionais utilizados na educação da Pessoa com Deficiência (PcD), em especial neste estudo, as pessoas com Transtorno do Espectro Autista (TEA). Trata-se de uma pesquisa qualitativa, a partir de um estudo exploratório na modalidade de Pesquisa Documental. Nosso objetivo neste artigo consistiu em realizar uma análise de imagens do corpo humano extraídas de cartões do Picture Exchange Communication System (PECS) disponíveis em um Blog de acesso público: http://pecsemportugues.blogspot.com/2008/06/corpo-humano.html. Os resultados demonstraram que: (i) invariavelmente, existem signos visuais e verbo-visuais arbitrários entre si, assim como apresentam signos que não apresentam correspondência direta entre o signo visual, a escritura e o corpo humano real; (ii) as imagens utilizadas no PECS, assim como quaisquer outras imagens, colonizam os aprendizes na prevalência de aspectos culturais não universais (não hegemônicos): cor da cútis, prevalentemente, branca; aspectos relacionados ao gênero e papéis sexuais masculinos e femininos, além do uso de estereótipos em relação a signos arbitrários que, não necessariamente, representam os diferentes contextos educativos da criança autista. Conclui-se, portanto, que a utilização dos cartões PECS requer cuidado e consideração semiológica por parte dos educadores.

Palavras-chave: análise semiológica; Picture Exchange Communication System (PECS); Barthes.

Abstract: Visual signs are present in instructional materials used in the education of people with disabilities (PCD), especially in this study, people with Autism Spectrum Disorder (ASD). This is a qualitative research, based on an exploratory study in the documentary research modality. Our objective in this article was to perform an analysis of human body images extracted from Picture Exchange Communication System (PECS) cards available on a PublicAccess Blog: 
http://pecsemportugues.blogspot.com/2008/06/corpo-humano.html. The results showed that: (i) there are invariably arbitrary visual and verb-visual signs, as well as show that signs that do not present a direct correspondence between the visual sign, the scripture and the real human body; (ii) the images used in pecs, as well as any other images, colonize the learners in the prevalence of non-universal (non-hegemonic) cultural aspects: predominantly white cutis color; aspects of gender-related and male and female sexual roles, in addition to the use of stereotypes in relation to arbitrary signs that do not necessarily represent the different educational contexts of autistic children. It is concluded, therefore, that the use of PECS cards requires care and semiological consideration by educators.

Keywords: semiological analysis; Picture Exchange Communication System (PECS); Barthes.

\section{INTRODUÇÃ̃}

A proposta do presente trabalho é problematizar representações, aparentemente, objetivas de uma dada realidade, usando a análise semiológica ao conteúdo "Corpo Humano" do acervo de cartões do Picture Exchange Communication System, doravante, PECS, disponibilizados pelo Blog http://pecsemportugues.blogspot.com/2008/06/corpohumano.html. O referido sítio tem ênfase em divulgar atividades com uso dos cartões do PECS e promover outras, como relatos de vivências e experiências acerca da pessoa com o Transtorno do Espectro Autista (TEA). Apresentaremos o artigo em quatro seções principais, a saber: a primeira, traz uma breve explanação acerca da Semiologia enquanto ciência, tendo Roland Barthes como principal autor; a segunda apresenta possibilidades do contexto comunicativo voltado à Pessoa com Deficiência (PcD), em especial, da pessoa com o TEA; a terceira apresenta a natureza do PECS à luz da teoria barthesiana. Por fim, a partir do referencial teórico apresentado, realizamos uma proposta de análise de um conjunto de imagens do corpo humano de cartões do PECS.

Foi a partir dos anos sessenta que a Semiótica ${ }^{1}$ começou a afirmar sua vocação à autonomia, fato que ocorreu paralelamente à possibilidade de reflexão geral acerca das condições de apreensão e produção da significação (GREIMAS, LANDOWSKI, 1986).

\footnotetext{
${ }^{1}$ Não é objetivo deste artigo aprofundar-se na teoria dos signos, mas uma ressalva deve ser feita no que ser refere aos termos "semiótica" e "semiologia". Tratam-se de termos que hora se equivalem, hora entram em disputa. "Semiologia" foi o termo usado pelo linguista Ferdinand de Saussure para descrever sua teoria geral dos signos, baseada num sistema binário do tipo "significante/significado". De outro modo, o termo "Semiótica" foi usado pelo filósofo Charles Sanders Pierce para descrever sua teoria geral dos signos baseada na tríade "objeto/signo/interpretante". Ao longo deste texto, usamos os termos como equivalentes, respeitando as escolhas de cada autor citado.
} 
Os referidos autores concordam que, enquanto Ciência do Signo, a Semiótica avançou no que se refere à construção de um conjunto robusto de procedimentos dedicados à análise concreta de objetos significantes - com ênfase inicial no campo linguístico, contudo progrediu significativamente para sistemas de significação não-linguísticos, reivindicando, assim, seu status enquanto teoria e metodologia. Dessa forma, a "teoria semiótica se tornou, pouco a pouco, mais complexa e rica, tal se deu, em larga medida, sob o impulso e sobre o controle da prática analítica" (idem, p.12).

Martine Joly (2005) nos ensina que a Semiologia se caracteriza no uso de seu recurso, isto é, trata-se de uma metalinguagem, um "discurso sobre", visto que seus questionamentos buscam a compreensão sobre ‘como' os sentidos são produzidos a partir de instrumentos e métodos que lhes são próprios. Historicamente, o termo Semiologia designava-se a um setor da Medicina, uma vez que a palavra tem origem grega, onde 'sémeion' refere-se à signo e, 'logos', à discurso, à ciência. De fato, a Semiologia Médica interpreta sinais no paciente, isto é, 'sintomas' ou um 'conjunto de sintomas' e é mais interessada em seus 'porquês' do que no 'como', já que este último é preocupação das Ciências Humanas.

Baseando-se em trabalhos de Umberto Eco, Joly salienta que a noção de signo existe desde a antiguidade a partir de Platão, mas aparece, particularmente, em Aristóteles. Apesar disso, esta noção de signo "não designa, todavia, 'a palavra'; esta é considerada um 'símbolo' constituído por sons e letras, ele mesmo estabelecido por convenção; o signo aproxima-se mais ainda da prova ou indício” (idem, p. 16, grifos nossos). Enquanto 'Teoria Geral dos Signos', a Semiologia teve início por volta dos anos 1900, com a proposição das teorias de Ferdinand de Saussure na Europa e de Charles Sanders Pierce nos Estados Unidos da América (JOLY, 2005).

A iniciativa ou ambição de uma ciência globalizante e geral que tratasse dos mais diferentes tipos de signos envolvidos na comunicação é do linguista e filósofo suíço Ferdinand de Saussure (1857-1913), considerado o fundador da linguística moderna. Ele considerou a língua como sendo formada por um complexo sistema de signos que expressam ideias e que a Semiologia poderia ser compreendida como a Ciência que estuda a vida de signos no interior da vida social. A nomeada Escola Americana, propiciada a partir dos trabalhos de C. S. Pierce, teve desenvolvimento em três vertentes: a $(i)$ 
Semiótica Pura que se reporta à filosofia da linguagem e à linguística; a (ii) Semiótica Descritiva que estuda comportamentos sociais não verbais e linguagens não verbais, de tradição behaviorista; e, por fim, a (iii) Semiótica Aplicada, de interesse pela pragmática e estuda as relações entre signos e indivíduos, incluindo a zoosemiótica ${ }^{2}$.

Na Europa, os pós-saussurianos são distinguidos pela maior ou menor ortodoxia linguística. Há a (a) Semiologia Comunicacional, dentro da qual os mais ortodoxos estudam, exclusivamente, a comunicação intencional que utiliza códigos com um número finito de elementos como as línguas, código Morse, etc. Além disso, há a (b) Semiologia da Significação, na qual os códigos podem ser considerados sistemas abertos e vagos enquanto campo de observação estruturado, desde que produza significados (JOLY, 2005).

São Roland Barthes e Christian Metz, no que se refere à imagem e ao cinema, os principais representantes franceses desta última corrente. A Semiologia, enquanto Ciência Geral dos Signos, é a ciência que se preocupa em decifrar os sistemas de signos e os processos de significação e interpretação destes, "interessar-se-á pela natureza da relação entre significante/significado, pelo funcionamento do signo no seu conjunto (estrutural contextual), quer seja linguístico ou não" (idem, p.24).

Roland Barthes (2005) define a Semiologia como a Ciência Geral do Signo, cujo objeto de estudo é o todo o Sistema Sígnico, independente de sua substância (cinema, som, imagem, rito, gestos, indumentária, etc.), ou seja, um sistema que é difundido pelos meios de comunicação de massa (mass media). De fato, compreende-se que ao tratar da leitura de imagem no ensino das ciências naturais escreve-se (ou fala-se) a respeito de um sistema de signos a partir de outro. Trata-se de uma limitação. Acerca disto, Santaella (2012) afirma que apenas seria possível explicar imagens a partir de outras imagens. Assim como esta autora, entendemos a polissemia da palavra 'leitura' para além da decodificação ou decifração de palavras e letras.

Assim, o ser humano realiza diariamente leituras do mundo e, na maioria das vezes, compreende-as. São leituras que vão desde a tela do smartphone, da televisão, de mapas,

\footnotetext{
${ }^{2}$ A zoosemiótica investiga os sistemas de comunicação (sinais visuais, químicos, tácteis e acústicos) utilizados pelos animais infra-humanos. Em web: http://www.cucsh.udg.mx/noticia/zoosemiotica Acesso em 21 jan.2021.
} 
de gráficos, de gestos, de narrativas visuais, das placas de nomes de ruas, dos signos do trânsito, até do sinal vermelho no semáforo, entre outros. De fato, o grau de compreensão e interpretação decorrentes das leituras das imagens depende de quão robusto é o acervo cultural que o seu expectador possui (BARTHES, 2005), o que pode possibilitar uma maior inserção de significantes por parte de quem produz um filme e, por extensão, um desenho, uma imagem, uma fotografia, um quadro, um cartum e, até mesmo, uma imagem de um livro didático.

Quadro 1. Integrantes do processo comunicativo de uma mensagem.

\begin{tabular}{|c|c|c|}
\hline Comunicação & \multicolumn{2}{|r|}{ O que o define? } \\
\hline $\begin{array}{l}\text { Quem emite } \\
\text { mensagem? }\end{array}$ & \multicolumn{2}{|c|}{$\begin{array}{l}\text { É o autor. No caso deste artigo, é o cartunista ou ilustrador. Há um } \\
\text { argumento geral, no qual o autor tem a incumbência de expor o estilo dado } \\
\text { à narrativa. A repetição ou criação de signos é dada dentro de determinados } \\
\text { limites para que o cartum ou ilustração fique inteligível, cuja fluência é } \\
\text { extraída de um tipo de léxico coletivo. }\end{array}$} \\
\hline $\begin{array}{l}\text { Quem recebe } \\
\text { mensagem? }\end{array}$ & \multicolumn{2}{|c|}{$\begin{array}{l}\text { É o público, cuja capacidade intelectiva da mensagem depende de um } \\
\text { repertório cultural específico. Quanto mais amplo e diverso for esse acervo } \\
\text { cultural, mais refinada será a intelecção/compreensão dos signos e símbolos } \\
\text { expressos na mensagem. }\end{array}$} \\
\hline \multirow{3}{*}{$\begin{array}{l}\text { Significante: sel } \\
\text { suportes remetem : } \\
\text { cenário, } \\
\text { indumentária, a }\end{array}$} & Heterogêneo & $\begin{array}{l}\text { Apela, mormente, à visão e, pode, também, apelar aos } \\
\text { aspectos tácteis. }\end{array}$ \\
\hline & Polivalente & $\begin{array}{l}\text { Um significante pode exprimir inúmeros significados, ou } \\
\text { seja, é polissêmico. Assim, um significado pode ser } \\
\text { expresso por vários significantes (sinonímia). }\end{array}$ \\
\hline & Combinatório & $\begin{array}{l}\text { Ele pode combinar signos presentes na narrativa com } \\
\text { outros que vão aparecendo ao longo desta. }\end{array}$ \\
\hline
\end{tabular}

Fonte: Adaptado de Barthes (2005)

Barthes (2012) destaca que nenhum sistema semiológico é autônomo em si mesmo, pois em algum momento de sua análise,

cruza com a linguagem. A substância visual, por exemplo, confirma suas significações fazendo-se reforçar por uma mensagem linguística (é o caso do cinema, da publicidade, dos comics, da fotografia de imprensa, etc.), de tal modo que pelo menos uma parte da mensagem icônica mantém uma relação estrutural de redundância ou de substituição com o sistema da língua (BARTHES, 2012, p.8, grifo nosso).

As imagens, em sua grande maioria, não carregam em si significados precisos enquanto Estatuto de Sistemas, uma vez que alcançam, exclusivamente, tal direito se sua substância for mediada pela língua "que recorta seus significantes (sob a forma de nomenclaturas) e nomeia os seus significados (sob a forma de usos ou de razões)" (BARTHES, 2012, p.8). Para enfrentar mensagens que são, ao mesmo tempo, evidentes 
e ambíguas, reveladoras e mascaradoras, fáceis de ler e enigmáticas, Barthes (2015, p.312) propõe uma leitura de três mensagens, tal como explicou no texto "Retórica da Imagem":

uma mensagem linguística, uma mensagem icônica codificada e uma mensagem icônica não codificada (...). É certo que a distinção das duas mensagens icônicas não se faz espontaneamente ao nível da leitura corrente: o espectador da mensagem recebe, ao mesmo tempo, a mensagem perceptiva e a mensagem cultural.

Metodologicamente, ler uma imagem a partir da semiologia de Barthes requer saber separar o que é icônico não-codificado ou literal, daquilo que é icônico codificado ou simbólico. Além disso, então, é preciso reconhecer em qual dos lados o texto tende a fixar a âncora do significado proposto pela imagem. A seguir trataremos da comunicação voltada à Pessoa com Deficiência $(\mathrm{PcD})$.

\section{COMUNICAÇÃO DIRIGIDA À PESSOA COM DEFICIÊNCIA}

A comunicação é um processo complexo de transmissão de informações utilizado pelo ser humano com o propósito de influenciar o comportamento daqueles que nos rodeiam, compartilhando informações, exprimindo desejos e necessidades. Esse processo contínuo que ocorre em um ambiente natural e no cotidiano pode ser preenchido por outras formas, que não só a linguagem verbal. Destacamos: a mímica, as expressões faciais, a orientação corporal, os gestos (como o indicar), os desenhos, os símbolos e as palavras que se materializam segundo uma forma multimodal (ORRÚ, 2012, p.64).

A comunicação verbal é o mais comum meio de comunicação entre os seres humanos. Contudo, nem todas as pessoas são capazes de verbalizar ou de utilizar a fala de modo que sejam compreendidas, como é o caso daquelas que se encontram impossibilitadas de falar ou de escrever, em virtude de sua incapacidade neuromotora, originada pela patologia que as constituem (ORRÚ, 2012, p.64).

O modo de pensar a função comunicativa da linguagem, descrito acima, ensejou a possibilidade de criação de um sistema de comunicação não verbal para as pessoas com deficiência em relação ao desenvolvimento da linguagem falada. Tais sistemas de comunicação são os que proporcionam expressão por meio de símbolos distintos da fala funcional de quem se comunica, sendo classificados em sistemas de comunicação sem ajuda e sistemas de comunicação com ajuda (BASIL, 1988). 
Para Orrú (2012), os sistemas classificados como "sem ajuda" não requerem nenhum instrumento ou auxílio técnico externo para que a comunicação se efetue e exprimem-se com (1) gestos de uso comum, pertencentes a uma comunidade (afirmação, negação com a cabeça, aceno com as mãos, etc.); (2) códigos gestuais não linguísticos (sistema de comunicação manual de tribos indígenas). Já os sistemas de comunicação "com ajuda" abarcam de forma ampla os elementos de representação, desde os iconográficos até os mais complexos e abstratos. São eles: (a) sistema com elementos muito representativos: objetos, fotografias, desenhos representativos; (b) sistemas construídos por desenhos lineares, como é o caso dos pictogramas.

A fim de que tais pessoas possam desenvolver a capacidade de exprimir seus pensamentos e sentimentos, foi desenvolvida a Comunicação Suplementar e/ou Alternativa (CSA) como um meio de comunicação que pode ser considerado uma verdadeira ferramenta de apoio ao professor, aos familiares e ao grupo social a que aqueles indivíduos pertencem. A CSA toma como referência todo o tipo de comunicação suplementar ou de suporte, especialmente baseada em símbolos gráficos e em tecnologias de apoio (nomeadamente os computadores e as interfaces específicas) de suporte ao processo de comunicação, permitindo a pessoa que se encontra nesta situação exceder os limites de parte de suas incapacidades, conforme o quadro e ritmo de cada um (ORRÚ, 2012).

De acordo com Chun (1991), não seria possível obter a história em detalhes a respeito do desenvolvimento da Comunicação Suplementar e/ou Alternativa no Brasil, já que os primeiros trabalhos sobre o assunto se encontram desconhecidos por terem sido registrados de maneira informal.

No ano de 1971, uma equipe de profissionais do Ontario Crippled Children's Centre, em Toronto, Canadá, desenvolveu um estudo dedicado à descoberta de um meio alternativo de comunicação dirigido a pessoas com distúrbios neuromotores, que não manifestavam a fala funcional. Até então, dos diversos métodos investigados em instituições especializadas para o processo de ensino/tratamento de crianças em circunstâncias semelhantes, todos se mostravam insatisfatórios, limitando o desempenho linguístico a poucos contextos, desprestigiando outras diversas situações de comunicação que poderiam ser aproveitadas (ORRÚ, 2012, p.66). 
Diante de tal situação, descobriram em "Signs and Symbols around the World", de Elizabeth Helfman, um sistema simbólico a nível internacional criado por Charles K. Bliss (baseado na escrita pictográfica chinesa e nas ideias do filósofo Leibniz), o Blissymbolics - Sistema Bliss de Comunicação. Seu objetivo era o de desenvolver uma maneira de criar uma linguagem universal entre os homens (desenvolvido entre 1942 e 1965), ou seja, um instrumento de comunicação mundial. Esse sistema não foi, inicialmente, destinado a pessoas com distúrbios de comunicação, começando apenas a ser usado com essa finalidade em 1971, depois de algumas adaptações realizadas juntamente com Charles Bliss e sua equipe canadense, cuja principal responsável era Shirley MacNaughton (CHUN; MOREIRA, 1997).

De acordo com Orrú (2012, p. 67), o termo Comunicação Suplementar e/ou Alternativa (CSA) é utilizado, portanto, para definir outras formas de comunicação como o uso de gestos, da língua de sinais, das expressões faciais, o uso de pranchas de alfabeto ou símbolos pictográficos e até o uso de sistemas sofisticados de computador com voz sintetizada. Dessa forma, essa opção de comunicação serviria como auxílio ao desenvolvimento da autonomia por meio de recursos tecnológicos, técnicas de inteligência artificial, como a utilização de esquemas montados por fotos, figuras extraídas de revistas, conforme o contexto e a necessidade a ser suprida.

Desta feita, a terminologia | básica define a CSA da seguinte forma: (1) Comunicação Aumentativa é toda comunicação suplementar à fala (vocal), isto é, são os gestos, a linguagem corporal, a expressão facial, comunicação gráfica, entre outros (BLACKSTONE, 1986). Além de, (2) Comunicação Suplementar e/ou Alternativa que se trata de uma área da prática clínica a qual tem por objetivo compensar, de forma temporária ou permanente, a incapacidade ou prejuízos de indivíduos com distúrbios severos na comunicação expressiva (ASHA,2020).

Há diversos sistemas simbólicos que estão englobados na CSA e que auxiliam o trabalho com pessoas com déficits nas habilidades de comunicação. Vários desses sistemas já vêm sendo incorporados a recursos de informática, que facilitam o armazenamento de símbolos, por exemplo, o Core Picture Vocabulary, o Picture Communication Symbols, o Pictogram Ideogram Communication System e o Picture Exchange Communication System (PECS). 


\section{A SUBSTÂNCIA DO PECS}

Um dos recursos que pode estimular a aquisição precoce da fala comunicativa em crianças com TEA $^{3}$ é o Picture Exchange Communication System (PECS). Após dificuldades ao longo dos anos com outros programas de comunicação, o PECS foi desenvolvido por Lori Frost e Andrew Bondy. O programa é pautado no Behaviorismo Radical proposto por B. F. Skinner, em que o aprendiz recebe alguma gratificação após parear corretamente uma imagem cartunizada ao seu correspondente real, ou selecionála a partir de um Mando (descritor utilizado para diferenciar outros “operantes verbais").

Essas alternativas de comunicação, a partir da utilização de sistemas de símbolos, permitem a representação do vocábulo e de imagens representativas de situações diversas que podem ser dispostas em cartões individuais, a serem fixados em uma prancha, agendas ou cadernos de comunicação, possibilitando a criação de frases, o apontamento que se deseja, a expressão de sentimentos, o conhecimento adquirido, a interação social. Trata-se de um sistema de treinamento em comunicação o desenvolvido no Delaware Autistic Program (DAP).

Uma das etapas principais na aprendizagem da criança autista é a aquisição da fala com finalidade comunicativa. O DAP foi pioneiro na utilização de um sistema fundamentado em imagens com crianças autistas a partir de 2 anos de idade como forma de comunicação inicial. No PECS, as crianças são estimuladas a entregar uma ficha com

\footnotetext{
${ }^{3} \mathrm{O}$ Transtorno do Espectro Autista (TEA) trata-se de deficiência complexa e duradoura, que se manifesta na primeira infância. $\mathrm{O}$ espectro, geralmente, é definido por uma gama de gravidades, compreendendo transtornos graves, leves e até mesmo aqueles não diagnosticados no exame clínico, que na condição de espectro afeta as pessoas de diferentes maneiras e em diferentes graus. O TEA pode ter influência direta nas habilidades: sociais, de comunicação, de relacionamentos e até a chamada autorregulação (AUTISM SOCIETY, 2020). O TEA tem como características essenciais: (a) padrões repetitivos e, mesmo, restritos de comportamento; (b) prejuízo persistente na interação social e na comunicação social recíproca; (c) afeta interesse e atividades. Assim, essas peculiaridades em conjunto afetam e limitam o funcionamento diário (DSM-5, 2014, p. 53). De fato, "Muitos indivíduos têm déficits de linguagem, as quais variam de ausência total da fala, passando por atrasos na linguagem, compreensão reduzida da fala, fala em eco até linguagem explicitamente literal ou afetada" (idem, p.53). Os sinais precoces da criança autista são: (i) começa a falar mais tarde que o normal ou não fala; (ii) faz repetições de fala ou mesmo de movimentos (por exemplo, bater palmas de forma sequenciada ou realizar movimentos repetidos); (iii) tem comportamento de forma a comunicação verbal atípica, evitando contato olho no olho, não responde com expressões faciais ou tem um tom monótono; (iv) prefere brincar sozinho a brincar com outras crianças; (v) a criança fica angustiada com mudanças - alimentares ou no seu cronograma, por menor que ela seja, por exemplo, alterar a marca do chocolate preferido ou do leite habitual; (vi) prefere jogos previsíveis e estruturados a brincadeiras do tipo "faz-de-conta"; (vii) a criança manifesta extremo interesse ou interesse rígido em tópicos específicos, por exemplo, parte de um determinado brinquedo (AUTISM SOCIETY, 2020; DSM-5, 2014).
} 
a imagem e um descritor a um parceiro comunicativo em troca do item real. Assim, se a criança seleciona ou é incentivada a selecionar a ficha que contém a imagem (fotográfica ou cartunizada) de uma maçã contendo o texto descrito "MAÇÃ", ela recebe a maçã (fruto) propriamente dita. O PECS, que está estruturado em seis Fases, possibilita a comunicação de crianças autistas não-verbais melhorando a comunicação. Assim, as crianças são estimuladas a dar um cartão de imagem em troca do item propriamente dito, iniciando o ato comunicativo dentro de um contexto social (BONDY, FROST, 1994) de forma a avançar para etapas de maior complexidade linguística.

Lembram estes autores que Skinner (1957) sugere que o 'Tato' (ou rotulação) é mantido por reforçadores sociais ou educacionais. No comportamento verbal, as ações de Tato referem-se a estímulos discriminativos não-verbais, por exemplo, reconhecer ou identificar um 'cavalo' ou a 'imagem de um cavalo' diante de um animal peludo, com visão bilateral, com cascos, crina, cauda etc. ou, de outro modo, saber descrever um cavalo na ausência dele: trote, texturas, relinchos, cheiros. Já o 'Mando', também na terminologia de Skinner (1957), não é controlado por reforçadores sociais ou educacionais. Ao apontar a imagem de uma maçã ou dizer maçã, a criança recebe uma maçã - não se trata de um reforçador controlado por reforçadores de base social.

Dessa forma, qual é a vantagem do PECS para a PcD com o TEA? Depois de um período de aprendizado, que pode variar de acordo com o espectro no qual a criança se encontra, com esta ferramenta ela consegue elaborar frases completas que podem culminar na construção de um texto compreensível. O PECS e seus efeitos vêm sendo investigados e utilizados em pesquisas recentes com resultados positivos com crianças pequenas que possuem o TEA e comportamento violento (HU, LEE, 2019).

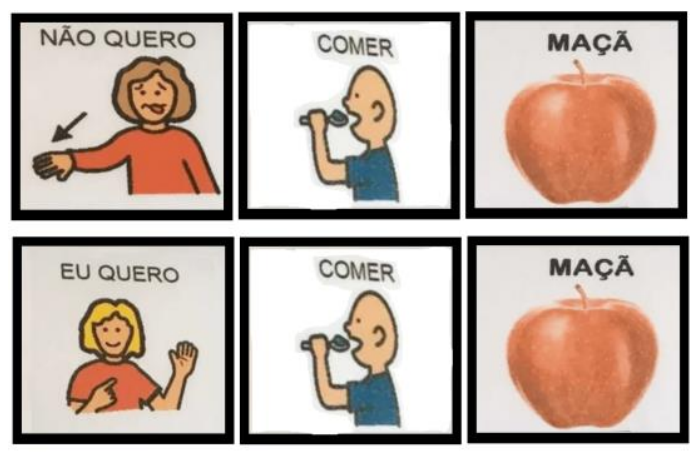

Recebido em: 18/01/2021

Aceito em: 24/02/2021 
Fonte: Fichário De Comunicação Alternativa. Em web https://produto.mercadolivre.com.br/MLB-1405251651-fichario-de-comunicaco-alternativaautismo-72-pecs-_JM Acesso em 20.01.2021

Figura 1. Exemplo de duas sequências dos cartões do Picture Exchange Communication System: "NÃO QUERO COMER MAÇÃ" e "EU QUERO COMER MAÇÃ"

O PECS “funciona” a partir de fichas ou cartões com imagens: uma fotografia colorida ou preto e branco, um pictograma, um cartum, um símbolo de trânsito, uma cor ou outras imagens e que contêm legendas que as descrevem. Assim, se a ficha contém a imagem de uma maçã, ela pode ter sido representada fotografada, cartunizada, na forma de pictograma, enfim, algo que funcione como signo - está no lugar de algo que não está presente (BARTHES, 2015). Ao representar algo que não está lá - o fotógrafo, o cartunista, o desenhista, enfim, aquele que produz ou escolhe uma dada imagem) - o faz de forma seletiva, recortando o que vai aparecer ou não na imagem, ou seja, o que vai ser representado e o que vai ser omitido, neste sentido, ele faz escolhas (LOIZOS, 2013; BANKS, 2009; SONTAG, 2004; ROSE, 2002).

Assim, ainda acerca da ficha da suposta e simples maçã contida na ficha do PECS, ela pode ser: (1) em relação à cor: vermelha, verde, amarela, bicolor, etc.; (2) em relação ao corte: pode aparecer representada em (a) vista lateral; (b) em corte longitudinal ou (c) corte transversal; (3) em relação ao plano da imagem: geralmente apresentada em closeup ou plano fechado; mas poderia aparecer em plano aberto (numa macieira) ou plano médio (numa cesta de maçãs); (4) poderia estar numa fase juvenil do desenvolvimento do pseudofruto, fase de colheita ou até em decomposição; (5) Poderia ter pedúnculo, folhas aparentes e até suas sementes; (6) poderia ser uma maçã importada ou uma maçã nacional; (7) poderia até ser aquele metafórico fruto do conhecimento ofertado pela serpente bíblica. Enfim, além dessas, seriam inúmeras as possibilidades de representação visual apenas para o descritor 'maçã'.

Portanto, a produção dos cartões do PECS exige representar objetos, ações, sentidos, cores, situações, regras, alimentos, animais, clima, pessoas, partes do corpo humano, noções de opostos e outros. Em conjunto, as fichas sozinhas do PECS muito pouco significam. Para usar uma expressão de Barthes (2011), por analogia, as fichas apresentam "presunções de sentido, formas, se assim quisermos, é o mundo que as 
preenche [...] são como elos de uma cadeia de sentidos" (p.16). É o contexto "in loco" do uso da comunicação com usos dos cartões do PECS que vai possibilitar o processo de significação.

Barthes (2009) destaca que todo signo implica ou inclui três relações. (1) A primeira delas é a "relação interior", que une o significante ao seu significado. Depois, há duas "relações exteriores", uma delas é chamada virtual e que vai unir o signo à "reserva específica de outros signos". A outra, "é actual, ela junta o signo aos outros signos do enunciado que o precedem ou lhe sucedem" (BARTHES, 2009, p.237). Para este autor, o primeiro tipo de relação ocorre no que comumente se chama de símbolo, primeira relação ou relação simbólica (por exemplo, o vermelho significa "PARE" ou a proibição de passar), "postulando um significado soberano, extraído quer de uma interioridade, quer de uma história" (BARTHES, 2011 p. 242-3).

Essa relação é estabelecida por convenção, por exemplo, o significante "OLHOS" (vocalização/fala/escrita/fotografia de olhos reais/ olhos cartunizados/ pictograma de olhos) está aderido, por convenção, ao seu significado (olhos reais). Para quaisquer variações do significante, o signo estará presente para o conjunto externo: esclera, íris, pupila, cílios, pálpebra inferior e superior.

Em seguida, (2) com relação à segunda relação ou Relação Paradigmática: "O segundo plano de relação implica a existência, para cada signo, de uma reserva ou 'memória' organizada de formas de que ele se distingue graças à mais pequena diferença necessária e suficiente para operar uma mudança de sentido" (BARTHES, 2011, p.237).

De outro modo, vermelho só tem significado de proibido avançar se ele estiver num semáforo e sistematicamente se opor à cor verde e ao amarelo e, mesmo na ausência de ambas, o vermelho faria oposição à ausência de cor - trata-se de relação paradigmática, ou seja, é uma relação virtual na qual o signo se une a uma reserva específica de outros signos, assim, exige daquele que consome a imagem uma reserva ou memória que o permita perceber diferenças para operar mudanças de sentido - pressupõe-se a comparação entre dois ou mais signos. 
Já (3) o terceiro plano de relação é chamado de relação sintagmática, no qual "o signo já não se situa entre seus 'irmãos' (virtuais), mas em relação aos seus 'vizinhos' (actuais)" (BARTHES, p. 238).

No plano de relação sintagmática, o signo sobrevive descolado de um contexto como ocorre na relação paradigmática, ele passa a estabelecer relações passageiras com outros signos, mas significante - trata-se do plano das associações, dos sintagmas - a relação está presente assim como as palavras em uma frase. Assim, é possível afirmar que o significado depende da relação passageira e para conceituar essa relação, o autor utilizase de uma analogia com vestimentas, como: "os elementos de uma roupa são associados segundo certas regras: vestir um suéter e um paletó de couro é criar entre essas duas peças uma associação passageira, mas significativa” (BARTHES, p.238).

Essa relação, portanto, busca ligações com outros signos - a construção de redes cuja combinação produz sentido, "ou mais geralmente um objeto novo" (idem, p,242). Estes vínculos estão presentes na comunicação com o uso contextualizado dos cartões do PECS utilizados com a ajuda de outra pessoa. Dessa forma, a criança interage mediante a assistência de outrem com os cartões e objetos reais. A "substância", para usar uma expressão de Barthes (2015), dos cartões do PECS são imagens simplificadas que, por terem essa natureza, necessariamente recorrem a estereótipos. Nossa premissa é que toda imagem figurativa tem relação direta com seu análogo real, embora essa relação se construa com nuances de conotação e denotação. Barthes chamou a atenção para o fato de que não separamos devidamente as nuances, a não ser que sejamos educados para isso. Decodificar o mundo a partir do signo que está expresso no cartão é prática que mobiliza um conhecimento cultural, sujeito à ideologia ou, nos termos de Barthes (2018; 2015), à mitologia contemporânea. Haveria máscaras sociais em um sistema aparentemente tão objetivo quanto o PECS?

\section{METODOLOGIA}

Este estudo se caracteriza por ser uma Pesquisa Qualitativa num delineamento de Pesquisa Documental do tipo exploratória. A modalidade tem inúmeras vantagens: documentos são fontes estáveis e ricas de dados, subsistem ao tempo, têm baixo custo e o contato com os sujeitos de pesquisa é indireto. As desvantagens relacionam-se à 
subjetividade dos documentos e à não-representatividade, contudo, esses últimos são aspectos que podem ser controlados pelo pesquisador (GIL, 2017). Assim, nesta modalidade de pesquisa, embora os dados sejam referentes a pessoas, eles são obtidos de forma indireta ou de maneira descolada de seu produtor, por exemplo, jornais, fotografias, desenhos, cartuns, registros estatísticos, filmes, discos, papéis oficiais, livros, músicas, entre outros. Em conjunto, estas fontes podem contribuir para elucidar a investigação de um dado fenômeno (idem).

Desta feita, apresentamos uma proposta de análise de trinta e um cartões do PECS relacionados ao conteúdo Corpo Humano (Figura 2), o corpus desta pesquisa. Utilizaremos, como proposta de análise semiológica, um recorte da sequência apresentada por Gemma Penn (2013) e Barthes (2012). Penn atesta que as análises semiológicas podem ser divididas em três etapas principais. A primeira, trata-se da escolha do material a ser utilizado. A segunda, refere-se à construção de um inventário denotativo e, por fim, a terceira, remete a uma análise dos níveis mais altos de significação (conotação e mito). Barthes $(2012$; 2009) atesta que a pesquisa semiológica objetiva reconstituir o funcionamento dos sistemas de significação da língua e a construção de "simulacro" dos objetos observados.

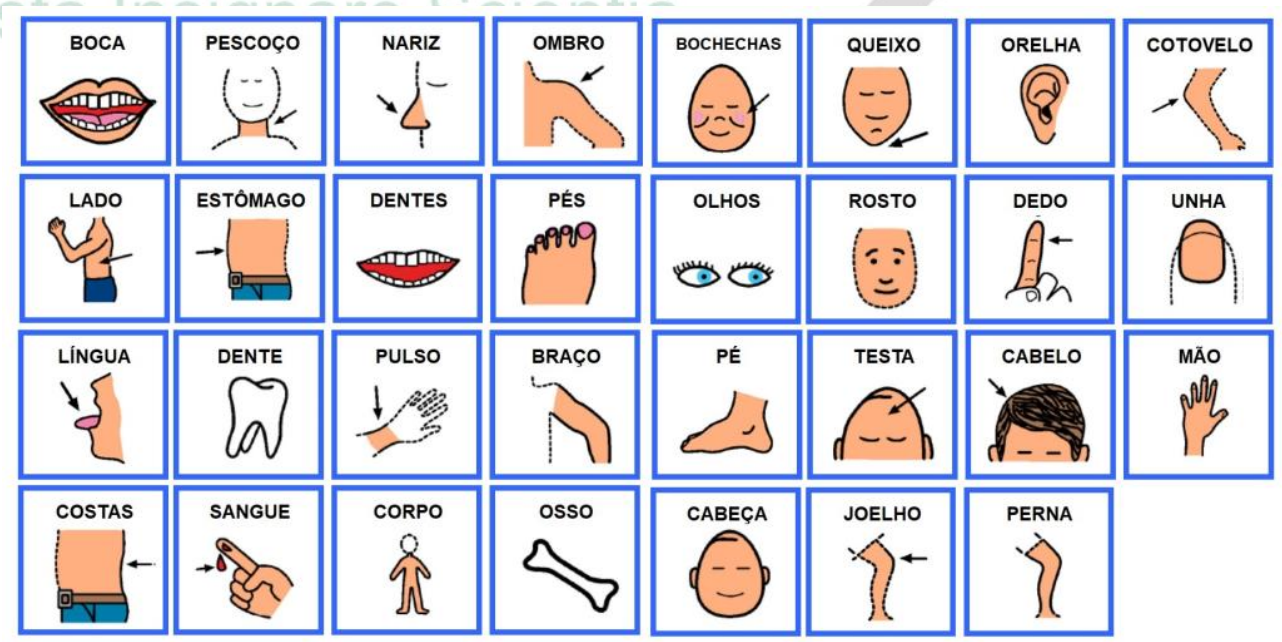

Figura 2 - Cartões do Picture Exchange Communication System considerados. Fonte: http://pecsemportugues.blogspot.com/2008/06/corpo-humano.html Acesso em 18.08.2020.

\section{RESULTADOS E DISCUSSÃO}

Recebido em: 18/01/2021

Aceito em: 24/02/2021 
A 1. ${ }^{a}$ etapa proposta por Penn (2013) relaciona-se à escolha do material a ser analisado. Assim, selecionamos o tema Corpo Humano, pois trata-se de um conteúdo que assume importância direta para a criança na compreensão e na forma como se relaciona com o próprio corpo. O Quadro 2 se refere à 2. ${ }^{a}$ etapa, ou seja, o inventário denotativo dos 31 cartões do PECS aqui considerados (como apresentado no Quadro 2).

Quadro 2: Inventário denotativo dos 31 cartões do PECS considerados.

\begin{tabular}{|c|c|c|}
\hline $\mathbf{N .}^{\mathbf{0}}$ & $\begin{array}{l}\text { Descrição do } \\
\text { texto } \\
\text { (escritura) }\end{array}$ & Descrição do texto-visual (imagem cartunizada) dos cartões do PECS \\
\hline 1 & BOCA & Desenho colorido de lábios entreabertos, dentes alinhados, língua e palato mole. \\
\hline 2 & PESCOÇO & $\begin{array}{l}\text { Contorno tracejado de uma cabeça sem cor, boca arqueada para cima e olhos } \\
\text { cerrados. Contorno tracejado de parte do torso. Área do pescoço preenchida } \\
\text { com a cor bege. }\end{array}$ \\
\hline 3 & NARIZ & $\begin{array}{l}\text { Representação de perfil, com contorno de parte da face tracejado. Olhos } \\
\text { cerrados. Seta em diagonal de cima para baixo indica nariz preenchido com a } \\
\text { cor bege. }\end{array}$ \\
\hline 4 & OMBRO & $\begin{array}{l}\text { Parte superior direita do dorso com contorno tracejado e preenchido com a cor } \\
\text { bege. Seta em diagonal de cima para baixo indica ombro com contorno } \\
\text { contínuo. }\end{array}$ \\
\hline 5 & BOCHECHAS & $\begin{array}{l}\text { Contorno de crânio oval preenchido com a cor bege, contorno de nariz, olhos } \\
\text { cerrados, boca arqueada para cima. Seta em diagonal de cima para baixo indica } \\
\text { bochechas demarcadas com contorno preto e preenchimento na cor rosa. }\end{array}$ \\
\hline 6 & QUEIXO & $\begin{array}{l}\text { Parte do contorno de crânio oval preenchido com a cor bege, olhos cerrados, } \\
\text { linha em arco indica o nariz, contorno de boca arqueada para baixo. Seta em } \\
\text { diagonal de cima para baixo indica o queixo. }\end{array}$ \\
\hline 7 & ORELHA & Pavilhão auricular direito preenchido com a cor bege, sem ligação com o crânio. \\
\hline 8 & COTOVELO & $\begin{array}{l}\text { Braço e antebraço esquerdos, preenchidos com a cor bege e contorno tracejado. } \\
\text { Seta em diagonal de baixo para cima indica cotovelo em traçado contínuo. }\end{array}$ \\
\hline 9 & LADO & $\begin{array}{l}\text { Parte do um torso masculino de perfil preenchido com a cor bege, com braço e } \\
\text { antebraço esquerdo semiflexionados, com calça azul marinho. Seta em diagonal } \\
\text { de cima para baixo indica a lateral esquerda do corpo, na região da cintura. }\end{array}$ \\
\hline 10 & ESTÔMAGO & $\begin{array}{l}\text { Parte de um torso masculino de perfil preenchido com a cor bege, trajando calça } \\
\text { jeans azul e cinto marrom. Costas aparecem tracejadas e seta horizontal indica } \\
\text { o abdômen com contorno contínuo. }\end{array}$ \\
\hline 11 & DENTES & $\begin{array}{l}\text { Representação delimitada pelo contorno inferior dos lábios, com dentes } \\
\text { alinhados e palato na cor vermelha. }\end{array}$ \\
\hline 12 & PÉS & Parte posterior de um pé esquerdo com unhas pintadas na cor rosa. \\
\hline 13 & OLHOS & Olhos arregalados com cílios, íris em destaque na cor azul. \\
\hline 14 & ROSTO & $\begin{array}{l}\text { Parte de uma cabeça com contorno tracejado preenchida com a cor bege, com } \\
\text { desenho de sobrancelhas, olhos abertos, nariz e boca arqueada para cima. }\end{array}$ \\
\hline 15 & DEDO & $\begin{array}{l}\text { Parte da mão esquerda apenas com contorno, dedo indicador preenchido com a } \\
\text { cor bege e apontando para cima. Há uma seta horizontal indicando-o. }\end{array}$ \\
\hline 16 & UNHA & $\begin{array}{l}\text { Dedo com contorno tracejado, sem preenchimento de cor e unha preenchida } \\
\text { com a cor bege. }\end{array}$ \\
\hline 17 & LÍNGUA & $\begin{array}{l}\text { Perfil de uma cabeça compreendendo a porção entre o nariz e o queixo, } \\
\text { preenchida com a cor bege e língua projetada para fora da boca e preenchida } \\
\text { com a cor rosa. Há uma seta em diagonal de cima para baixo indicando-a. }\end{array}$ \\
\hline 18 & DENTE & Representação de um dente molar inferior com três raízes. \\
\hline
\end{tabular}




\begin{tabular}{|c|c|c|}
\hline 19 & PULSO & $\begin{array}{l}\text { Representação de parte do antebraço e mão esquerda tracejados e sem } \\
\text { preenchimento de cor. Seta vertical, de cima para baixo, indica o pulso, } \\
\text { preenchido com cor bege. }\end{array}$ \\
\hline 20 & BRAÇO & $\begin{array}{l}\text { Parte do torso foi representada com contorno tracejado e sem cor. Braço e parte } \\
\text { do antebraço esquerdos representados com contorno contínuo e preenchidos } \\
\text { com a cor bege. }\end{array}$ \\
\hline 21 & PÉ & Representação de um pé direito de perfil, preenchido com a cor bege. \\
\hline 22 & TESTA & $\begin{array}{l}\text { Parte superior de uma cabeça calva e preenchida com a cor bege, olhos cerrados } \\
\text { e parte das orelhas aparentes. Uma seta diagonal, de cima para baixo, indica a } \\
\text { testa. }\end{array}$ \\
\hline 23 & CABELO & $\begin{array}{l}\text { Parte superior de uma cabeça, olhos cerrados e parte das orelhas aparentes. } \\
\text { Cabelos preenchidos com a cor marrom. Uma seta diagonal, de cima para baixo, } \\
\text { indica os cabelos. }\end{array}$ \\
\hline 24 & МÃO & Mão esquerda espalmada e preenchida com a cor bege. \\
\hline 25 & COSTAS & $\begin{array}{l}\text { Parte de um torso masculino de perfil preenchido com a cor bege, trajando calça } \\
\text { jeans azul e cinto marrom. Abdômen com contorno tracejado e costas com } \\
\text { contorno contínuo. Seta horizontal indica as costas. }\end{array}$ \\
\hline 26 & SANGUE & $\begin{array}{l}\text { Mão direita preenchida com a cor bege, com punho fechado e dedo indicador } \\
\text { apontando em ângulo de } 45 \text { graus. Representação de um corte no dedo e uma } \\
\text { gota preenchida com a cor vermelha. Uma seta horizontal indica esta gota. }\end{array}$ \\
\hline 27 & CORPO & $\begin{array}{l}\text { Representação simplificada de um corpo, composto por cabeça, tronco e } \\
\text { membros. Cabeça com contorno tracejado e sem preenchimento. Torso e } \\
\text { membros com contorno contínuo e preenchidos com a cor bege. }\end{array}$ \\
\hline 28 & OSSO & Osso com contorno preto, sem preenchimento e extremidades simétricas. \\
\hline 29 & CABEÇA & $\begin{array}{l}\text { Cabeça oval e predominantemente calva, com contorno contínuo e preenchida } \\
\text { na cor bege. Olhos cerrados, boca arqueada para cima, orelhas aparentes e uma } \\
\text { mecha de cabelo sobre a testa. }\end{array}$ \\
\hline 30 & JOELHO & $\begin{array}{l}\text { Representação da perna entre coxa e tornozelo, com contorno tracejado e } \\
\text { preenchida com a cor bege. A área do joelho tem contorno contínuo. Uma seta } \\
\text { horizontal aponta para o joelho. }\end{array}$ \\
\hline 31 & PERNA & $\begin{array}{l}\text { Representação da perna entre coxa e tornozelo, com contorno contínuo entre } \\
\text { coxa e tornozelo e preenchida com a cor bege. }\end{array}$ \\
\hline
\end{tabular}

A 3. ${ }^{a}$ Etapa proposta por Penn (2013) prevê a análise dos níveis mais altos de significação, conotação e mito. Ela relembra que, para decodificar tais signos é preciso remeter a convenções universais. Cabe considerar que o universal, não raro, invoca estereótipos e que o processo de significação se concretiza nos usos e contextos. Assim, a primeira narrativa apresentada para a criança que possui o TEA é perceber-se em um mundo branco, caucasiano e ocidental, isto é, sem variações da cor da cútis (sempre representada na cor bege), formatos e cor de olhos, cabelos ou desenho do nariz, por exemplo. Esse é o mito do discurso imagético do PECS, que naturaliza ou torna invisível a ideologia do colonizador sobre o colonizado, porque o mito não esconde, mas mostra a realidade de forma sectária, exibindo a parte hegemônica como se fosse o todo (BARTHES, 2018; PENN, 2013). 
Figura 3: "O Mito Hoje"

\begin{tabular}{|c|l|l|l|}
\hline $\begin{array}{c}\text { Sistema de } \\
\text { Primeira } \\
\text { Ordem }\end{array}$ & $\begin{array}{l}\text { 1.Significante } \\
\text { Imagem: pessoa } \\
\text { branca. }\end{array}$ & $\begin{array}{l}\text { 2.Significado } \\
\text { conceito: pessoa do } \\
\text { sexo masculino ou } \\
\text { feminino com pouca } \\
\text { melanina na pele. }\end{array}$ & $\begin{array}{l}\text { 1. SIGNIFICADO (II) } \\
\text { *Todo ser humano (homem ou } \\
\text { mulher) é branco, é esguio, é } \\
\text { otimista (sorri), tem olhos } \\
\text { azuis e dentes perfeitos e } \\
\text { alinhados [...]. } \\
\text { Todo homem usa calças. Toda } \\
\text { mulher pinta as unhas. Todo } \\
\text { uso da cor azul é masculino e, } \\
\text { da cor rosa, feminino. }\end{array}$ \\
\hline $\begin{array}{c}\text { Sistema de } \\
\text { Orgunda }\end{array}$ & 0 & $\begin{array}{l}\text { 3. Signo: pessoa branca } \\
\text { Imagem: homem ou mulher brancos. }\end{array}$ \\
\hline
\end{tabular}

Fonte: adaptado de Barthes (2018) e PENN (2017).

Essa ausência de variação sígnica, especialmente em crianças com o TEA, pode criar expectativas distintas das esperadas nos processos educativos. Para citar alguns exemplos: chamar de LÍNGUA, enquanto órgão da cavidade oral, apenas aqueles órgãos provenientes de pessoas brancas. O mesmo ocorre ao apresentar OSSO com desenho semelhante ao fêmur (mas que na verdade mais se parece com um osso ofertado aos cães de desenhos animados) e não em outros formatos. Se o íleo, mandíbula ou o frontal forem apresentados, podem não ser reconhecidos como OSSO, por não terem o formato apresentado no cartão ou até por terem sido representados sem relação direta com o corpo humano.

Outra leitura esperada no conjunto destes cartões é que todo o tracejado (que no ambiente escolar, em outras atividades poderia indicar local de dobra ou da indicação de recortar ou mesmo preencher com lápis) e a cor branca signifiquem área 'sem importância' ou 'ausente' para a leitura dos cartões do corpo humano.

Estão presentes erros conceituais dos conteúdos de Ciências do corpo humano: (1) No cartão ESTÔMAGO, a seta indica o abdômen; (2) No cartão CORPO, a indicação é de um corpo decapitado, como se a cabeça não fizesse parte do corpo; (3) PÉ e PÉS aparecem recortados em planos distintos, ao menos parece que a ficha PÉS refere-se a “DEDOS DOS PÉS” ou "UNHAS DOS PÉS". 
Parece haver uma regra: o corpo humano é reduzido à representação cultural do corpo disciplinado: os corpos estão vestidos (calça jeans, cinto de couro com fivela larga) e os órgãos genitais são ausentes. A representação do corpo feminino só aparece "aos pedaços": boca, unhas pintadas de rosa e cílios proeminentes. Rosto, dorso etc. são masculinos. A pessoa branca obesa é representada para indicar BOCHECHAS. Note-se que ROSTO, QUEIXO E CABEÇA são representados por pessoas magras. A representação sectária também alcança a representação cultural dualista do corpo versus mente ou corpo versus cabeça/cérebro. A boca é quase sempre arqueada para cima, legitimando apenas o sorriso e o otimismo. Os OLHOS são femininos e assustados. Poderiam ser tranquilos, desafiadores. A representação da BOCA é tipicamente estereotipada: lábios carnudos, dentes brancos e perfeitamente alinhados, como na publicidade de creme dental. Anatomicamente, a boca não é restrita à abertura oral ou pelo conjunto apresentado por lábios, dentes, língua e o que se parece com o palato.

\section{CONSIDERAÇÕES FINAIS}

Nossa proposta foi realizar, a partir da proposta semiológica francesa e a luz do referencial Barthesiano, uma análise semiológica dos cartuns do conteúdo "Corpo Humano" constante de cartões do Picture Exchange Communication System. Das análises realizadas, verificamos que os estereótipos ali presentes criam uma representação mascarada da realidade que pretendem comunicar. A partir disso, questionamo-nos se é função do PECS colonizar a pessoa com deficiência (PcD).

Ao unir imagem e legenda, cada cartão tende a "ancorar" a representação em um significado: boca só pode ser sorrindo, corpo só pode ser caucasiano e magro, dentes só podem ser alinhados e assim por diante. Por mais simples e de fácil decodificação que os signos apresentados pareçam, percebemos que a imagem e legenda apresentadas nos cartões dialogam entre si e, inseridos no contexto de uso, permitem uma leitura acurada destas imagens que não se restringe apenas a seus aspectos denotativos).

Barthes, ao refletir acerca de imagens fotográficas, aponta que sempre existem funções (intenções) para sua existência, visto que as imagens podem: "informar, representar, surpreender, fazer significar, dar vontade" (BARTHES, 2010, p. 48-49). Nesse sentido, as figuras analisadas podem contribuir para a criação de uma fala (mítica):

“Todo ser humano (homem ou mulher) é branco, é esguio, é otimista (sorri), tem olhos 
azuis e dentes perfeitos e alinhados [...] Todo homem usa calças. Toda mulher pinta as unhas. Todo uso da cor azul é masculino e, da cor rosa, feminino. ”;

As leituras das imagens são contextualizadas no uso dos cartões do PECS, contudo, as imagens carregam sentidos e remetem ao seu sítio de produção (ROSE, 2002). Dessa forma, qual foi o objetivo do autor destas imagens? A produção destas, parte de um contexto e ótica da pessoa branca caucasiana? Parte também de uma visão estereotipada do ser humano (esguio, olhos azuis, corpos apresentados dentro da norma [nunca (im)perfeitos?], dentes alinhados)? Além de uma visão estereotipada de gênero e papéis sexuais? Por que os corpos estão vestidos? O dualismo corpo/mente está presente quando o ilustrador separa a cabeça do corpo ou apenas denota uma incompreensão anatômica do ilustrador?

Existiram limitações neste trabalho de pesquisa justamente porque não consideramos todas as postagens (e imagens dos cartões) constantes em todas as publicações do Blog mencionado. A análise de todas as imagens e suas relações sígnicas demandarão estudos futuros.

A análise destas imagens dos cartões do PECS demonstra a necessidade da implementação de disciplinas nos cursos de formação de professores (também da área de Ciências) que favoreçam a leitura crítica de mídia. A semiologia/semiótica permitiria desvelar mensagens presentes nos mais diferentes meios: na TV, no livro didático (textos e fotografias), em vídeos, músicas, web, entre outras.

Como lembra Barthes (2018), o mito é uma fala despolitizada, que existe não para esconder algo, pelo contrário, é para mostrá-lo de forma clara e inequívoca, carrega uma construção ideológica que lhe dá sentido. No campo da denotação vê-se nos cartões do PECS pessoas brancas, homens e mulheres, cartunizadas e representando partes do corpo humano. No sentido conotativo, os processos de significação decorrentes da uniformidade dos corpos apresentados nestes cartões produzem outras leituras possíveis? As narrativas apresentadas a partir do corpo humano (também cultural) podem ser ingênuas se desconsiderarmos as intenções de quem as produziu? Apesar de toda a simplicidade da linguagem utilizada nos cartuns e os usos dos estereótipos na criação de representações da sociedade, estas escolhas têm impacto na educação da Pessoa com Deficiência (PcD) 
ou na forma como educadores as orientam e ensinam? Quais lições as imagens dos cartões do PECS dão em si mesmas?

No livro "Crítica e Verdade" (2011), Barthes diz que não cabe à crítica explicar o sentido da mensagem, mas sim descrever o funcionamento do "sistema produtor de significação" e que se dedicou a essa tarefa, movido por uma profunda impaciência com a naturalização daquilo que é cultural. Nada escapa à ideologia, como esta singela análise demonstrou. O caminho está aberto para a impaciência crítica daqueles que lidam com o campo da comunicação suplementar e alternativa.

\section{REFERÊNCIAS}

ASHA. American Speech Language Hearing Association (ASHA). Augmentative and Alternative Communication. Em web: https://www.asha.org/PracticePortal/Professional-Issues/Augmentative-and-Alternative-Communication/ Acesso em: 16 ago.2020.

AUTISM SOCIETY. What is autism? https://www.autism-society.org/what-is/ Acesso em: 25 set/2020.

BANKS, Marcus. Dados visuais para a pesquisa qualitativa. Porto Alegre: ArtMed, 2009. 176p.

BARTHES, Roland. Ensaios Críticos. Lisboa: Edições 70, 2009.

BARTHES, Roland. Elementos de Semiologia. São Paulo: Cultrix, 2012.

BARTHES, Roland. O óbvio e o obtuso. Lisboa: Edições 70, 2015.

BARTHES, Roland. Inéditos. Vol. 3 - imagem e moda. São Paulo: Martins Fontes, 2005 .

BARTHES, Roland. A Câmera Clara, Porto: Edições 70, 2010.

BARTHES, Roland. Mitologias, Porto: Edições 70, 2018.

BARTHES, Roland. Crítica e Verdade. São Paulo: Perspectiva, 2011.

BASIL, Carmen. Interacción social em usuários de sistemas de comunicación no vocal: Comunicación Alternativa. FUNDESCO, Madrid, 1985.

BASIL, Carmen. Sistemas de comunicación no-vocal: Clasificación y conceptos básicos. En: C. Basil y R. PUIG (Eds.): Comunicación Aumentativa. Curso sobre sistemas y ayudas técnicas de comunicación no-vocal. Madrid: INSERSO, Col. Rehabilitación, 1988.

BAUER, Martin W.; GASKELL, George. Pesquisa qualitativa com texto, imagem e som: um manual prático. Petrópolis, RJ: Editora Vozes, 2013, pp.137-155.

BLACKSTONE, Sarah. W. Augmentative Communication: An introduction. Rockville: American Speech-Language-Hearing Association, 1986. 
BONDY, Andrew S.; e FROST, Lori A. The Picture Exchange Communication System. Focus on Autistic Behavior, V. 9, N. 3, p.1-19, 1994.

CHUN, Regina Yu Shon. O desenvolvimento da comunicação não - verbal através dos símbolos Bliss em indivíduos não falantes portador de paralisia cerebral. Distúrbios da comunicação, 4: 121 - 136, São Paulo, outubro, 1991.

CHUN, Regina Yu S.; MOREIRA, Elaine C. Comunicação Suplementar e/ou Alternativa - ampliando possibilidades de indivíduos sem fala funcional. Em: LACERDA, C.B.F.; PANHOCA, I. (Org). Tempo de Fonoaudiologia. Taubate/SP, 1997, v, p. 97-113.

DMS-5. Manual diagnóstico e estatístico de transtornos mentais [recurso eletrônico]. DSM-5 / [American Psychiatric Association; tradução: Maria Inês Corrêa Nascimento ... et al.]; revisão técnica: Aristides Volpato Cordioli ... [et al.]. - 5. ed. - Dados eletrônicos. - Porto Alegre: Artmed, 2014.

GIL, Antônio Carlos. Como elaborar projetos de pesquisa. $6 .{ }^{a}$ Edição. São Paulo: Atlas, 2017. 192p.

GREIMAS, Algirdas J., LANDOWSKI, Erick. Análise do discurso em ciências sociais. São Paulo: Global, 1986.

HU, Xiaoyi; LEE, Gabrielle. Effects of PECS on the Emergence of Vocal Mands and the Reduction of Aggressive Behavior Across Settings for a Child with Autism. Behavioral Disorders, V. 4, N. 44, p. 215-226, 2019.

JOLY, Martine. Introdução a Análise da Imagem. Lisboa: Edições 70, 2005.

LOIZOS, Peter. Vídeo, filme e fotografias como documentos de pesquisa. Em: BAUER, M.W.; GASKELL, G. Pesquisa qualitativa com texto, imagem e som: um manual prático. Petrópolis, RJ: Editora Vozes, 2013, pp.137-155.

ORRÚ, Sílvia Ester. Autismo, linguagem e educação: interação social no cotidiano escolar. 3 ed. Rio de Janeiro: Wak Ed; 2012,188p.

PENN, Gemma. Análise semiótica de imagens paradas. Em: Bauer, Martin W. e Gaskell, George. Pesquisa Qualitativa com Texto, Imagem e Som: um Manual Prático. Petrópolis, Vozes, 2011.

ROSE, Gillian. Visual methodologies: an introduction to the interpretation of visual materials. London: SAGE, 2002. 229p.

SANTAELLA, Lúcia. Leitura de imagens. São Paulo: Melhoramentos, 2012.

SKINNER, Burrhus Frederic. Verbal behavior. Englewood Cliffs, NJ: Prentice-Hall, 1957.

SONTAG, Susan. Sobre fotografia. São Paulo: Companhia da Letras, $2004{ }^{\text {i }}$

${ }^{i}$ Os autores agradecem a conferência, a dedicação, as sugestões de alteração e a correção linguística realizada por Paola Natacha Bogusz. Contato: pbogusz84@gmail.com 